\title{
Transinfection of Wolbachia in the Mediterranean Flour Moth, Ephestia kuehniella, by Embryonic Microinjection
}

\author{
TETSUHIKO SASAKI* \& HAJIME ISHIKAWA \\ Department of Biological Sciences, Graduate School of Science, University of Tokyo, \\ Hongo, Tokyo 113-0033, Japan
}

\begin{abstract}
Wolbachia are maternally transmitted intracellular bacteria found in many arthropod species. They cause a reproductive incompatibility called cytoplasmic incompatibility (CI) in several hosts, including the Mediterranean flour moth, Ephestia kuehniella. Two strains of E. kuehniella, one from Yokohama city and the other from Tsuchiura city, express different levels of CI: the Yokohama strain expresses CI at a higher level than the Tsuchiura strain. In order to determine whether the difference of CI levels depends on Wolbachia or the host, we performed transinfection experiments in E. kuehniella by means of embryonic microinjection, and successfully transferred Wolbachia carried by the Yokohama strain into the Tsuchiura strain, from which the original Wolbachia had been removed by tetracycline treatment. The resulting transinfected strain expressed CI at a level near that of the Yokohama strain, suggesting that, in these strains of E. kuehniella, the level of CI is determined by Wolbachia rather than by the host.
\end{abstract}

Keywords: cytoplasmic incompatibility, embryonic microinjection, Ephestia kuehniella, Wolbachia.

\section{Introduction}

Wolbachia are maternally transmitted bacteria found in many insects and other arthropods. Wolbachia infections often lead to reproductive alterations of the hosts, including thelytokous parthenogenesis, feminization of genetic males into functional females, malekilling and cytoplasmic incompatibility (CI) (reviewed in Stouthamer et al., 1999). CI is a reproductive incompatibility that results in the death of the embryo. In the simplest case, CI is expressed when Wolbachia-infected males mate with uninfected females.

The strength of CI varies among host species (Bourtzis \& O'Neill, 1998). Almost complete incompatibility has been observed in flour beetles of the genus Tribolium (Wade \& Steven, 1985), the almond moth Ephestia cautella (Brower, 1976; Kellen et al., 1981; Sasaki \& Ishikawa, 1999) and the small brown planthopper Laodelphax striatellus (Noda, 1984). Weak expressions of CI have been reported for Drosophila melanogaster (Hoffmann et al., 1994), D. sechellia (Giordano et al., 1995) and D. ananassae (Bourtzis et al., 1996). The strength of CI also varies even within a species depend-

*Correspondence. E-mail: sasaki@biol.s.u-tokyo.ac.jp ing on the Wolbachia variant (Merçot et al., 1995). Some Wolbachia that infect $D$. simulans induce relatively strong CI (Hoffmann et al., 1986; O'Neill \& Karr, 1990), while others do not induce detectable CI (Rousset \& Solignac, 1995; Hoffmann et al., 1996; Bourtzis et al., 1998; Merçot \& Poinsot, 1998).

Does the level of CI vary due to the difference in Wolbachia or hosts? To answer this question, investigators have transferred Wolbachia between different hosts. In some experiments, Wolbachia transferred into new hosts expressed CI as they did in their natural hosts, suggesting that the strength of CI largely depends on Wolbachia (Rousset \& De Stordeur, 1994; Giordano et al., 1995; Sinkins et al., 1995; Clancy \& Hoffmann, 1997). On the other hand, other experiments supported the view that the host plays an important role in the determination of the CI level. When a Wolbachia variant known to induce strong CI was transferred from D. simulans into D. melanogaster, the transferred Wolbachia did induce CI in D. melanogaster but at a lower level than in D. simulans (Boyle et al., 1993). Poinsot et al. (1998) performed the converse transinfection, namely from $D$. melanogaster to $D$. simulans, and reported that the resulting transinfected lines expressed almost complete CI, even though the donor D. melanogaster showed only weak CI. 
We previously examined Wolbachia infection in two strains of the Mediterranean flour moth Ephestia kuehniella, one from Yokohama city and the other from Tsuchiura city. Both strains were infected with Wolbachia that belonged to the A group designated by Werren et al. (1995). Phylogenetic analysis based on the wsp gene, the gene coding for a Wolbachia surface protein (Braig et al., 1998), suggested that the two Wolbachia variants are closely related: there was only one synonymous nucleotide substitution between the two sequences. Crossing experiments showed that the Yokohama-strain males expressed significantly higher levels of CI in both intrastrain and interstrain crosses with uninfected females than did the Tsuchiura-strain males (Sasaki \& Ishikawa, 1999). Does the difference in the CI levels expressed by the two strains depends on Wolbachia or the host? In the present study, in an attempt to answer this question, we performed transinfection experiments in E. kuehniella by means of embryonic microinjection, and successfully transferred Wolbachia from the Yokohama strain to the Tsuchiura strain. The level of CI expressed by the transinfected strain was comparable to that of the donor strain.

\section{Materials and methods}

\section{Insects}

Two laboratory strains of the Mediterranean flour moth Ephestia kuehniella were reared on a diet consisting of wheat bran, dried yeast and glycerol (20:1:2 w/w) at $25^{\circ} \mathrm{C}$ with a 16 -h light: 8 -h dark photoperiod. They had been collected originally in Yokohama and Tsuchiura, cities located in the central part of the main island of Japan, and have since been maintained in laboratories for several years. Wolbachia-uninfected strains were established by rearing the insects on a diet containing tetracycline at a final concentration of $0.04 \%(w / w)$ for two generations (Sasaki \& Ishikawa, 1999). All strains were maintained under uncrowded conditions at a density of about one larva per $0.5 \mathrm{~g}$ of the diet.

\section{Microinjection}

Injections were performed at room temperature using a microscope (Nikon SMZ-U) equipped with a 3D micromanipulator (Narishige MMN-1) and a microinjector (Narishige IM-6). A $1 \times 90 \mathrm{~mm}$ Pyrex glass capillary was pulled in a Narishige needle puller (PN-3), and the tip was cut manually with a razor to make an angled point with a diameter of about $8 \mu \mathrm{m}$. The microneedle was connected to the microinjector by a Teflon tube filled with water.
Freshly laid eggs $(<1-\mathrm{h}$ old $)$ of the uninfected Tsuchiura strain were attached to a piece of doublesided tape on a slide. The eggs were aligned near the edge of the tape with a small paint brush. Ovaries of the donor strain (Yokohama strain) collected by dissection from the adult females were also placed on a piece of double-sided tape on a slide. The ooplasm taken out of the donor ovary was injected into one end of each recipient egg at random because the posterior and anterior ends of the ellipsoidal egg of E. kuehniella can not be clearly distinguished. This protocol allowed us to inject approx. 50 eggs per hour. The injected eggs on the slide were placed in a plastic dish $(9-\mathrm{cm}$ diameter $)$ containing a piece of moist filter paper, and kept at $25^{\circ} \mathrm{C}$. Five days after injection, the sticky surface of the tape was covered with flour, and the slide was transferred onto the diet in a plastic container. The eggs hatched on the sixth or seventh day after injection. Because the larvae moved into the diet, counting the cast-off shells left on the tape checked the rate of egg hatching.

Adults emerged about one month after eggs hatched. Females were then transferred individually into $30 \mathrm{~mL}$ plastic cups and mated with males. The males used were either those developed from the injected eggs or those collected from the stock culture of the uninfected Tsuchiura strain. Eggs laid by each female were diagnosed for infection status by PCR.

\section{Diagnostic PCR for detection of Wolbachia}

The presence or absence of Wolbachia was tested by diagnostic PCR assays using Wolbachia-specific primers for the $f t s Z$ bacterial cell-cycle gene. The template DNA for PCR was prepared from eggs or larvae by the crude STE boiling method (O'Neill et al., 1992). Ten to 20 eggs were homogenized in $50 \mu \mathrm{L}$ of STE [100 mм NaCl, $10 \mathrm{~mm}$ Tris- $\mathrm{HCl}$ (pH 8.0), 1 mm EDTA (pH 8.0)] containing $0.4 \mathrm{mg} \mathrm{mL}^{-1}$ proteinase $\mathrm{K}$, and incubated for $90 \mathrm{~min}$ at $55^{\circ} \mathrm{C}$ followed by $15 \mathrm{~min}$ at $95^{\circ} \mathrm{C}$. After brief centrifugation, $1 \mu \mathrm{L}$ of the supernatant was used as the template DNA for PCR. In order to prepare DNA from a single egg, the volume of the extraction solution was reduced to $15 \mu \mathrm{L}$. A larva was first homogenized in 100 $\mu \mathrm{L}$ of STE without proteinase $\mathrm{K}$, and $10 \mu \mathrm{L}$ of the homogenate was added to $90 \mu \mathrm{L}$ of STE containing proteinase $\mathrm{K}$.

PCR was performed in a $20 \mu \mathrm{L}$ reaction mixture using Takara EX Taq. The primers were ftsZAdf $\left(5^{\prime}\right.$-CTC AAG CAC TAG AAA AGT CG-3') and ftsZAdr (5'-TTA GCT CCT TCG CTT ACC TG-3'), which amplify the fts $Z$ gene of A-group Wolbachia (Werren et al., 1995). PCR cycling conditions were $94^{\circ} \mathrm{C}$ for 3 min followed by 35 amplification cycles of $94^{\circ} \mathrm{C}$ for 
$30 \mathrm{~s}, 55^{\circ} \mathrm{C}$ for $30 \mathrm{~s}$ and $72^{\circ} \mathrm{C}$ for $1 \mathrm{~min}$, and finally $72^{\circ} \mathrm{C}$ for $5 \mathrm{~min}$.

\section{Crossing experiments}

The adults of E. kuehniella do not feed, and survive for about one week. During this period, the female mates once or twice. Crossing experiments were performed using single pairs of virgin individuals. As the male larvae are easily distinguished by dark patches (the testes) on the back, we separated the females and males during the late larval stages. A female and a male, younger than 3 days after emergence, were set in a 30-mL plastic cup and left there for 3 days. Most females deposited more than 100 eggs onto the wall of the cup. Cups in which fewer than 50 eggs had been laid were discarded. From each pair, 50-100 eggs were collected and placed onto $1 \%$ agarose in a plastic dish $(35-\mathrm{mm}$ diameter). After incubation for $6-7$ days at $25^{\circ} \mathrm{C}$, the hatching rate was scored for each single pair cross. The data were analysed by Mann-Whitney $U$-tests.

\section{Results}

\section{Establishment of transinfected strain}

The ooplasm of Wolbachia-infected females of the Yokohama strain was injected into uninfected eggs of the Tsuchiura strain. Out of 321 injected eggs, 127 eggs hatched and 54 females and 41 males emerged. Insects that developed from the injected eggs were designated as generation $0(\mathrm{G} 0)$. The first 50 females that emerged were mated to males for egg collection, while the four females that emerged later were discarded.

The presence of Wolbachia in the G1 eggs was examined by diagnostic PCR. At first, 10-20 eggs collected from each female were tested in bulk. In this first assay, we detected Wolbachia in 13 broods, which were named line 1 to line 13 , respectively (Table 1 ). The
Wolbachia-positive broods were then subjected to the second assay in which four eggs from each brood were tested individually. Nine broods, of which all the eggs examined were infected, were pooled as a transinfected strain. Three broods, lines 3, 8 and 11, comprised both infected and uninfected eggs. These were maintained separately, and their G2 eggs were re-examined by the same assays as performed on G1 eggs (Table 2). Testing eight broods for each line, we obtained nine infected broods that were added to the transinfected strain, which had been obtained by pooling the 9 broods of infected G1 eggs.

\section{Cl expressed by the transinfected strain}

The transinfected strain was reared and PCR assayed to ensure that the infection was stable at G3 and G8. All of the 16 larvae selected at random for each generation were infected. The adult males of G3 and G8 were tested for the expression of CI by crossing them with the uninfected Tsuchiura-strain females (Fig. 1). CI expressed by the naturally infected males of the Tsuchiura and Yokohama strains were also examined simultaneously with the crossing experiment of G8 males. The

Table 2 Wolbachia infection in the G2 eggs of transinfected E. kuehniella Tsuchiura

\begin{tabular}{lcccccc}
\hline & \multicolumn{2}{c}{ First assay } & & \multicolumn{2}{c}{ Second assay } \\
\cline { 2 - 3 } Line & $\begin{array}{c}\text { No. of } \\
\text { broods }\end{array}$ & Infection & & $\begin{array}{c}\text { No. of } \\
\text { broods }\end{array}$ & $\begin{array}{c}\text { Infection } \\
\text { ratio }\end{array}$ \\
\hline Line 3 & 5 & - & & & 4 \\
Line 8 & 3 & + & & & 4 \\
Line & 4 & 4 & + & & & 4 \\
& 6 & - & & & 4 \\
\hline
\end{tabular}

Table 1 Wolbachia infection in E. kuehniella Tsuchiura injected with egg cytoplasm of E. kuehniella Yokohama

\begin{tabular}{|c|c|c|c|c|c|}
\hline \multicolumn{2}{|c|}{ G0 females } & \multicolumn{2}{|c|}{$\begin{array}{l}\text { First assay } \\
\text { of G1 eggs }\end{array}$} & \multicolumn{2}{|c|}{$\begin{array}{l}\text { Second assay } \\
\text { of G1 eggs }\end{array}$} \\
\hline $\begin{array}{l}\text { No. of } \\
\text { females }\end{array}$ & $\begin{array}{c}\text { Egg } \\
\text { collection }\end{array}$ & $\begin{array}{l}\text { No. of } \\
\text { broods }\end{array}$ & Infection & $\begin{array}{l}\text { No. of } \\
\text { broods }\end{array}$ & $\begin{array}{l}\text { Infection } \\
\text { ratio }\end{array}$ \\
\hline 6 & unsuccessful & & & & \\
\hline \multirow{5}{*}{44} & successful & 31 & - & & \\
\hline & & 13 & + & 9 & $4 / 4$ \\
\hline & & & & 1 (Line 8) & $3 / 4$ \\
\hline & & & & $2($ Lines $3 \& 11)$ & $1 / 4$ \\
\hline & & & & 1 (Line 9) & $0 / 4$ \\
\hline
\end{tabular}


Fig. 1 Cytoplasmic incompatibility expressed by Ephestia kuehniella. Uninfected females of the Tsuchiura strain were crossed with transinfected males of generation 3 (a), transinfected males of generation 8 (b), infected Yokohama-strain males (c), infected Tsuchiura-strain males (d), and uninfected Tsuchiura-strain males (e).

levels of CI expressed by the transinfected strain were significantly different from those expressed by the naturally infected Tsuchiura strain $(\mathrm{G} 3$ and Tsuchiura: $U=229, \quad P<0.05 ; \quad G 8$ and Tsuchiura: $U=509$, $P<0.001)$. On the other hand, no significant difference in CI levels was observed among G3, G8 and the Yokohama strain.

\section{Discussion}

In the present study, we transferred Wolbachia between infected and uninfected strains of E. kuehniella by embryonic microinjection. To our knowledge, this is the first report of a successful transfer of Wolbachia in Lepidopteran insects.

To date, protocols of Wolbachia transfer have been developed for isopods and several species of insects. In isopods, Wolbachia can be transferred via the haemolymph by injection of homogenized tissues (Juchault et al., 1994) and by simple wound-to-wound contact (Rigaud \& Juchault, 1995). Grenier et al. (1998) reported a method for the transfer of Wolbachia in Trichogramma wasps, in which purified Wolbachia from an infected donor was microinjected into pupae developed in vitro. In Drosophila (Boyle et al., 1993) and Tribolium confusum (Chang \& Wade, 1994), Wolbachia have been transferred by egg-toegg microinjection. In a preliminary experiment, we conducted a haemolymph transfer in E. kuehniella. However, no infected line was obtained, suggesting that Wolbachia rarely or never reaches the germline via the haemolymph in this insect (our unpubl. obs.), and leading us to perform embryonic microinjection.

PCR assays of G1 eggs showed that three broods consisted of a mixture of infected and uninfected eggs. This imperfect transmission occurred probably because

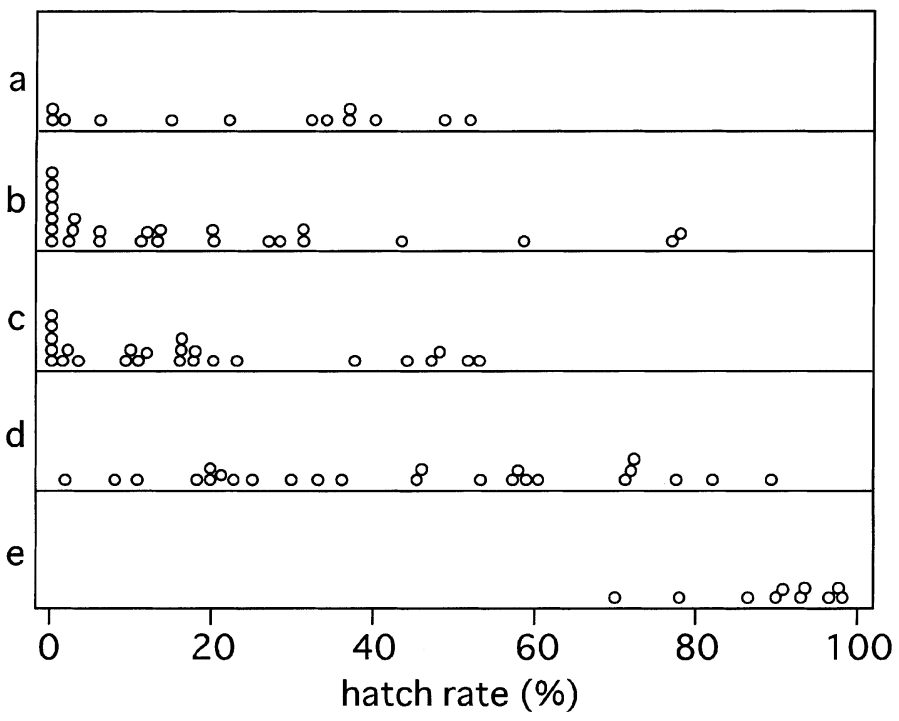

the amount of injected ooplasm was insufficient to infect all the germline cells with Wolbachia. However, such infection polymorphism within a brood disappeared in G2. Almost complete infections were also observed in both G3 and G8: i.e. all of the randomly selected larvae were shown to be infected by the PCR assay. The level of CI expressed by G3 males was comparable to that expressed by G8 males, suggesting that the transferred Wolbachia increased in number in the new host within 4 generations $(\mathrm{G} 0-\mathrm{G} 3)$ and remained stable thereafter.

In comparison with naturally infected strains, the transinfected strain expressed CI at a level close to that of the donor strain. Accordingly, it was concluded that the difference in CI levels expressed by the Yokohama and Tsuchiura strains was due to differences in Wolbachia rather than in the host insects. Besides the difference in CI levels, the two strains of E. kuehniella differ in the colour of the adults, the duration of the larval development, and the sensitivity to a high larval density during rearing (our unpubl. obs.). Although there must thus be some genetical differences between the two strains, the difference in CI levels seems to be independent of the host nuclear background. In the crosses using the naturally infected Tsuchiura-strain males, the strength of CI varied greatly and the hatching rates of two crosses were higher than $80 \%$ (Fig. 1). This may lead one to suspect that there were some uninfected individuals in the population of the Tsuchiura strain. To eliminate this possibility, we examined the infection rate by testing 100 eggs randomly selected from the stock culture. All eggs were infected, suggesting that the maternal transmission rate is very high and that uninfected individuals seldom appear.

In this transfer experiment, we obtained 13 transinfected broods out of 321 injected eggs. The relatively 
high yield of transinfected lines, in addition to the relatively easy protocol, increases the feasibility of using E. kuehniella for transinfection experiments. While we transferred Wolbachia intraspecifically in this work, it may be possible to apply the protocol to interspecific transfers of Wolbachia.

Among Lepidoptera, three distinct phenotypes of reproductive alterations have been observed. Wolbachia induce CI in E. cautella (Brower, 1976; Kellen et al., 1981) and in E. kuehniella (Sasaki \& Ishikawa, 1999). Wolbachia-mediated male-killing has been reported in the butterfly Acraea encedon (Hurst et al., 1999). In the Asian corn borer Ostrinia furnacalis, a phenomenon of feminization caused by a cytoplasmic agent was observed (Kageyama et al., 1998), and this agent was revealed to be Wolbachia (Kageyama et al., pers. comm.). Using these insects, it may be possible to transfer Wolbachia between hosts expressing different reproductive alterations in order to examine the roles played by Wolbachia and genetic background of host in determining the phenotype. Although each Wolbachia variant may be specialized to its natural host species to some degree, Wolbachia may be successfully transferred within the same order of Lepidoptera. In Dipteran insects, successful interfamily transfer has been reported between Aedes albopictus and D. simulans (Braig et al., 1994).

\section{Acknowledgements}

This study was partly supported by a Grant-in-Aid for Scientific Research from the Ministry of Education, Science, Sports and Culture of Japan (10740388).

\section{References}

BOURTZIS, K. AND O'NEILL, S. L. 1998. Wolbachia infections and arthropod reproduction. Bioscience, 48, 287-293.

BOURTZIS, K., DOBSON, S. L., BRAIG, H. R. AND O'NEILL, S. L. 1998. Rescuing Wolbachia have been overlooked. Nature, 391, $852-853$.

BOURTZIS, K., NIRGIANAKI, A., MARKAKIS, G. AND SAVAKIS, C. 1996. Wolbachia infection and cytoplasmic incompatibility in Drosophila species. Genetics, 144, 1063-1073.

BOYLE, L., O'NEILL, S. L., ROBERTSON, H. M. AND KARR, T. L. 1993. Interspecific and intraspecific horizontal transfer of Wolbachia in Drosophila. Science, 260, 1796-1799.

BRAIG, H. R., GUZMAN, H., TESH, R. B. AND O'NEILL, S. L. 1994. Replacement of the natural Wolbachia symbiont of Drosophila simulans with a mosquito counterpart. Nature, 367, 453-455.

BRAIG, H. R., ZHOU, W., DOBSON, S. AND O'NEILL, S. L. 1998. Cloning and characterization of a gene encoding the major surface protein of the bacterial endosymbiont Wolbachia pipientis. J. Bacteriol., 180, 2373-2378.

BROWER, J. H. 1976. Cytoplasmic incompatibility: occurrence in a stored-product pest Ephestia cautella. Ann. Entomol. Soc. Am., 69, 1011-1015.

CHANG, N. W. AND WADE, M. J. 1994. The transfer of Wolbachia pipientis and reproductive incompatibility between infected and uninfected strains of the flour beetle, Tribolium confusum, by microinjection. Can. J. Microbiol., 40, 978-981.

CLANCY, D. AND HOFFMANN, A. A. 1997. Behavior of Wolbachia endosymbionts from Drosophila simulans in Drosophila serrata, a novel host. Am. Nat., 149, 975-988.

GIORDANO, R., O'NEILL, S. L. AND ROBERTSON, H. 1995. Wolbachia infections and the expression of cytoplasmic incompatibility in Drosophila sechellia and D. mauritiana. Genetics, 140, 1307-1317.

GRenier, S., PINTUREAU, B., HedDi, A., LASSAbliere, F., JAGER, C., LOUIS, C. ET AL. 1998. Successful horizontal transfer of Wolbachia symbionts between Trichogramma wasps. Proc. R. Soc. B, 265, 1441-1445.

HOFFMANN, A. A., ClANCY, D. J. AND DUCAN, J. 1996. A naturally-occurring Wolbachia infection in Drosophila simulans that does not cause cytoplasmic incompatibility. Heredity, 76, 1-8.

HOFFMANN, A. A., ClANCY, D. J. AND MERTON, E. 1994. Cytoplasmic incompatibility in Australian population of Drosophila melanogaster. Genetics, 136, 993-999.

HOFFMANN, A. A., TURELli, M. AND SimMONS, G. M. 1986. Unidirectional incompatibility between populations of Drosophila simulans. Evolution, 40, 692-701.

HURST, G. D. D., JIGGINS, F. M., VON DER SCHULENBURG, H. G. J., BERTRAND, D., WEST, S. A., GORIACHEVA, I. I. ET AL. 1999. Male-killing Wolbachia in two species of insect. Proc. $R$. Soc. B, 266, 735-740.

JUChAUlt, P., FRElon, M., BOUCHON, D. AND RIGAUd, T. 1994. New evidence for feminizing bacteria in terrestrial isopods: evolutionary implications. C. R. Acad. Sci. Paris, 317, 225-230.

KAGEYAMA, D., HOShIZAKI, S. AND ISHIKAWA, y. 1998. Femalebiased sex ratio in the Asian corn borer, Ostrinia furnacalis: evidence for the occurrence of feminizing bacteria in an insect. Heredity, 81, 311-316.

KELLEN, W. R., HOFFMANN, D. F. AND KWOCK, R. A. 1981. Wolbachia sp. (Rickettsiales: Rickettsiaceae) a symbiont of the almond moth, Ephestia cautella: ultrastructure and influence on host fertility. J. Invertebr. Pathol., 37, 273-283.

MERÇOT, H., LLORENTE, B., JACQUES, M., ATLAN, A. AND MONTCHAMP-MOREAU, C. 1995. Variability within the Seychelles cytoplasmic incompatibility system in Drosophila simulans. Genetics, 141, 1015-1023.

MERÇOT, H. AND POINSOT, D. 1998. \& discovered on Mount Kilimanjaro. Nature, 391, 853.

NODA, H. 1984. Cytoplasmic incompatibility in allopatric field populations of the small brown planthopper, Laodelphax striatellus, in Japan. Entomol. Exp. Appl., 35, 263-267.

O'NEILL, S. L., GIORDANO, R., COLBERT, A. M. E., KARR, T. L. AND ROBERTSON, H. M. 1992. 16S rRNA phylogenetic analysis of the bacterial endosymbionts associated with cytoplasmic 
incompatibility in insects. Proc. Natl. Acad. Sci. U.S.A., 89, 2699-2702.

O'NEILL, S. L. AND KARR, T. L. 1990. Bidirectional incompatibility between conspecific populations of Drosophila simulans. Nature, 348, 178-180.

POINSOT, D., BOURTZIS, K., MARKAKIS, G., SAVAKIS, C. AND MERÇOT, H. 1998. Wolbachia transfer from Drosophila melanogaster into D. simulans: host effect and cytoplasmic incompatibility relationships. Genetics, 150, 227-237.

RIGAUd, T. AND JUCHAUlt, P. 1995. Success and failure of horizontal transfer of feminizing Wolbachia endosymbionts in woodlice. J. evol. Biol., 8, 249-255.

Rousset, F. AND DE STORdeur, E. 1994. Properties of Drosophila simulans strains experimentally infected by different clones of the bacterium Wolbachia. Heredity, 72, 325-331.

ROUSSET, F. AND SOLIGNAC, M. 1995. Evolution of single and double Wolbachia symbioses during speciation in the
Drosophila simulans complex. Proc. Natl. Acad. Sci. U.S.A., 92, 6389-6393.

SASAKI, T. AND ISHIKAWA, H. 1999. Wolbachia infection and cytoplasmic incompatibility in the Almond moth and the Mediterranean Flour moth. Zool. Sci., 16, 739-744.

SINKINS, S. P., BRAIG, H. R. AND O'NEILL, S. L. 1995. Wolbachia superinfections and the expression of cytoplasmic incompatibility. Proc. R. Soc. B, 261, 325-330.

STOUTHAMER, R., BREEUWER, J. A. J. AND HURST, G. D. D. 1999. Wolbachia pipientis: microbial manipulation of arthropod reproduction. Ann. Rev. Microbiol., 53, 71-102.

WADE, M. J. AND STEVENS, L. 1985. Microorganism mediated reproductive isolation in flour beetles (genus Tribolium). Science, 227, 527-528.

WERREN, J. H., ZHANG, W. AND GUO, L. R. 1995. Evolution and phylogeny of Wolbachia: reproductive parasites of arthropods. Proc. R. Soc. B, 261, 55-71. 